\title{
Fostering Positive Transfer through Metalinguistic Awareness: A Case for Parallel Instruction of Synonyms in L1 and L2
}

\author{
Ekaterina Talalakina \\ National Research University Higher School of Economics \\ Correspondence concerning this article should be addressed to Ekaterina Talalakina, National Research \\ University Higher School of Economics, B. Ordinka, 47/7, Moscow, Russian Federation, 115035. \\ E-mail: etalalakina@hse.ru
}

\begin{abstract}
Numerous studies on transfer in language learning focus on the nature of transfer, its mechanisms, and its impact on language proficiency and literacy. The majority of implications for teaching methods concern interpretive skills such as reading, whereas the data on effective transfer strategies related to productive skills such as speaking are scarce. This study focuses on speech development based on metacognitive knowledge built into L1 (Russian) as a tool for fostering transfer regarding language universals into L2 (English). An intervention experiment involving elementary school students was based on parallel instruction of synonyms as explicit metalinguistic knowledge. The findings show that, in contrast to the control group, participants from the experiment group displayed a significantly higher gain in skills regarding synonyms in L2, even though metacognitive knowledge of the subject was presented in L1. The results of the study suggest that metalinguistic awareness can facilitate transfer and its instruction can be an effective teaching strategy in speech development in early childhood education.
\end{abstract}

Keywords: cross-language transfer, metalinguistic awareness, synonyms, primary education

Studies of language transfer (or cross-linguistic influence) have long proven that the belief about keeping L2 classes free from L1 due to its potential negative interference is ungrounded and outdated (Odlin, 1989; Gass \& Selinker, 1993; Ringbom, 2007; Jarvis \& Pavlenko, 2008). Although 'the persuasiveness of certain types of errors has been among the most significant counterarguments against importance of transfer', such phenomenon as positive transfer should not be overlooked (Odlin, 1989, p.3).Along the same lines, Corder (1993) stresses that 'the mother tongue comes into act as a heuristic tool in the discovery of the formal properties of the new language, facilitating especially the learning of those features which resemble features of the mother tongue' (p. 29). Thus, in defining positive transfer, the key role belongs to cross-linguistic similarities, which can be 'overwhelmingly facilitative' (Ringbom, 2007 , p. 18). The objective of the present study is to examine a successful strategy of fostering positive transfer in L2 classroom.

Theoretical background of the study includes the analysis of such phenomena as cross-linguistic transfer in bilingual education, metalinguistic awareness in general, synonyms as language universals in particular, and teaching for transfer. The most significant studies concerning these concepts serve as underlying assumptions in the design of the present experimental classroom-based research. The experiment includes the analysis of teaching materials in Russian elementary education, the design of special materials for the intervention, the pre- and post-testing of participants $(\mathrm{N}=86)$ in intervention and control classes. The findings are discussed in terms of the impact of working with synonyms to facilitate transfer of metalinguistic knowledge and skills for the overall gain in L1 and L2 speech development.

\section{Materials and Methods}

\section{Positive Transfer in L2 Classes}

When it comes to methodology of L2 teaching, it is essential to recognize that 'one of the primary purposes of L1 use in the FL classroom is to facilitate positive transfer and the internalization of new 
concepts' (Jarvis \& Pavlenko, 2008, p. 217). Even though, according to Ringbom (2007), positive transfer occurs on item, system, and overall level within a natural bilingual environment as well as in formal schooling, both subconsciously and consciously, we are mostly interested in a mechanism of fostering positive transfer in a formal learning setting, which is closely related to literacy. In this case, as it is noted by Odlin (1989), 'the comparative success of literate bilinguals does not as clearly indicate the importance of language transfer in the sense of native language influence as it indicates the importance of transfer of training' (p. 134).

Transfer of training, defined by Odlin (1989) as influences on the production or comprehension of a second language that are due to the ways learners have been taught', raises the question of interdisciplinary nature of transfer in L2 classroom andcalls for establishing links between language, cognition, and learning. One of such links manifests itself in metalinguistic awareness, which unites the concepts of system level language transfer and transfer of training.

\section{Metalinguislic Awareness}

Jessner (2006) defines metalinguistic awareness as 'the ability to focus attention on language as an object in itself or to think abstractly about language and, consequently, to play with or manipulate language' (p. 42). In other works, metalinguistic awareness is also referred to as 'metalinguistic knowledge' or 'language awareness' (Jarvis \&Pavlenko, 2008), 'linguistic awareness' (Odlin, 1989), and 'metalinguistic abilities' (Tunmer et al., 1988). Despite the differences in terminology, the key idea here is knowledge about the language as a system and the functions of its elements. For the purposes of the present study, it is assumed that all these terms are interchangeable.

Metalinguisitic awareness is gradually built in L1 in the early childhood (Allan, 1982) and developed in connection to first reading achievement (Tunmer et al., 1988), oral fluency, and bilingualism (Bialystok \& Ryan, 1985), as well as formal L1 instruction (Zipke, 2008). Additionally, research by Boulware-Gooden et al. (2007) revealed that employing metacognitive strategies such as building semantic webs connecting parts of speech, synonyms, antonyms, and other related words (which can also qualify as a metalinguistic awareness strategy) enhances reading comprehension and vocabulary achievement in third-grade students of L1. Hence, becoming literate in L1 is closely connected to acquiring metalinguistic awareness, which can be potentially transferred not only into L2.

Transferability of metalinguistic skills from L1 to L2 is illustrated in studies by Royer and Carlo (1991), and Anton and Dicamilla (1999) related to a receptive skill of reading and a productive skill of speaking, respectively. Furthermore, in the study by Harrarte (1998), transfer into L3 was also tracked in testing Grade 5 and Grade 8 students on metalinguistic knowledge including synonymy. At the same time, Vygotsky (1934) pointed to a reverse transfer of metalinguistic awareness from L2 to L1:

It has been shown that a child's understanding of his native language is enhanced by learning a foreign one. The child becomes more conscious and deliberate in using words as tools of his thought and expressive means for his ideas. [ ...] The child's approach to language becomes more abstract and generalized' (p. 160).

This reinforces the idea of an early formation of metalinguistic skills in children, be it in L1 or L2.

\section{Synonyms as Language Universals}

The basic consideration of the link between language and cognition lends itself into a discussion of how word information is organized in the mind of an individual. It is generally acknowledged and verified through word association tests that there are two types of relations that connect words in the mind: syntagmatic and paradigmatic (Ringbom, 2007). Syntagmatic relations reflect the way words are used in speech within collocations and sentences, while paradigmatic relations show connections within semantic webs that group words according to the same topic, polysemy, synonymy, antonymy, etc. Both types of links refer to implicit knowledge, i.e. 'the knowledge that individuals may not be aware of but which researchers can infer from their systematic verbal performance' (Jarvis \& Pavlenko, 2008, p. 118). Meanwhile, explicit knowledge assumes definitions and rules that individuals are aware of and capable of verbalizing on demand (Jarvis \& Pavlenko, 2008, p. 118).

Accordingly, in case of synonymy, this linguistic concept is originally formed in the mind of an individual in the form of implicit knowledge as a mere reflection of reality. Fess (1938) stressed that 'indeed, the main reason why we have synonyms is a human one, that is, because both individuals and society are complex made up of differing and sometimes conflicting elements, each calling for its own expression in words' (p. 347). Meanwhile, synonyms are an essential part of metalinguistic knowledge (explicit knowledge) both in L1 and L2. To illustrate, talking about L1 learning, Jessner (2006) highlights that 'when metalinguistic performance is considered from the output side, the emphasis is on producing synonymity and grammaticality judgments, pointing out ambiguity, locating errors, explaining word choice, etc.' (p. 52). 
From L2 perspective, an interesting conclusion involving implicit and explicit knowledge of synonymy was made by Furnas as far back as in 1908:

The study of synonyms involves also a rigorous mental discipline and forces one to think in the foreign language, the much-desired goal of every language student. As another by-product might be mentioned a cultivation of feeling for the language. A native imbibes naturally a certain feeling for distinctions in words, but a foreigner must use all the stilts available in order to cultivate this feeling, so that here again we find the study of synonyms invaluable (p. 118).

The skill of synonyms recognition and use is beyond doubt in its value in L2 acquisition. As highlighted by Ringbom (2007), deeper involvement in manipulation of information leads to more effective learning. Along with that synonyms also play a key role in inferencing during reading and overcoming lexical insecurity expressed by repetitions during speaking (Jessner, 2006). Consequently, the understanding of their functions in the speech of others and the ability to replicate their proper use in one's own speech can serve as assign of L2 proficiency.

In the light of language transfer, one of the most important universalist assumptions is that there are categories applicable to the analysis of all languages (Odlin, 1989). Given the nature of synonymy as a linguistic phenomenon rooted in the mind of an individual (first subconsciously and then reinforced explicitly through formal schooling), synonyms can serve as language universals, metalinguistic knowledge of which can contribute to positive transfer between L1 and L2. In this case, we are dealing with both systemlevel transfer (transfer of knowledge about functions of language units) and transfer of training (transfer of skills related to the utilization of those language units in speech).

\section{Teaching for Transfer}

Summarizing the facilitative transfer theories, Royer (1979) distinguishes between environmental and cognitive theories, arguing that the former provide moreeducationalutilityin terms of providingguidelines for instructional events. Indeed, the question of what learning conditions are more conducive of transfer is key in the pragmatic value of transfer research. One of the conceptual answers is provided by Perkins and Salomon (2012), who promote a motivational view of transfer by stressing the shift from a learning culture of demand to a learning culture of opportunity supported by expansive framing concept by Engle et al. (2012). When it comes to dual language education, Cummins (2005) singles out five major types of cross-language transfer: transfer of conceptual elements, transfer of metacognitive strategies, transfer of pragmatic aspects of language use, transfer of specific linguistic elements, transfer of phonological awareness (p. 3). To encourage a combination of various types of transfer the author suggests creating dual language teaching materials and inter-classes collaboration both carried out through multimedia. However, within the framework of this highly topical approach, a more specific question arises as to what exact teaching strategies can be used in the class-room?

Although interdependence theories in bilingual education have been tested several times to prove the connection between L1 and L2 literacy (Verhoeven, 1994; Cárdenas-Hagan, Carlson, \& Pollard-Durodola, 2007), there is an evident gap in the literature on particular effective teaching methods to foster positive cross-linguistic transfer. Thus, the present study aims at testing a particular instructional strategy designed to foster positive transfer through parallel instruction of metalinguistic skills and builds on the following premises articulated in the previous research in the field of teaching for transfer: (1) 'metalinguistic knowledge and awareness of this knowledge play a crucial role in the development of individual multilingualism' (Jessner, 2008, p. 270); (2) cognitive development of children of 7 years of age and above allows working with metalinguistic skills including synonymy (Van Kleeck, 1982; Bialystok, 1986); (3) concurrent instruction of L1 and L2 in primary school has a positive effect on cross-linguistic transfer (Van der Leij, Bekebrede, \& Kotterink, 2010).

\section{Study Design}

This classroom-based study was conducted in two elementary schools in Moscow, Russia. The peculiarity of the educational setting in the chosen schools consists in the fact that, by the third grade, when the instruction of L2 (English, in this case) starts, students display a relatively homogenous mastery of L1 (Russian).

The hypothesis of the study was formulated as follows: under the conditions of parallel explicit instruction of synonyms in L1 and L2, students are able to display signs of positive transfer of training related to the use of synonyms in reading and speaking. Particular objectives of the study included the following: (1) to analyze the current curriculum in Russian (L1) and English (L2) in two schools in relation to the use of synonyms and building related metalinguistic knowledge; (2) to design learning materials taking into the consideration active vocabulary (vocabulary that appears in textbooks students use) in L1 and L2; (3) to conduct intervention experiment and assess its results. 


\section{Learning Materials}

The first task of the study deals with the analysis of learning materials third graders use in L1 and L2. Two elementary schools were chosen specifically because they differed in their choice of available textbooks in both languages. The textbooks were analyzed both in terms of quantitative and qualitative representation of synonyms. The quantitative analysis included the following parameters: (1) availability of language material suitable for special focus on synonyms (the number of synonyms in textbook vocabulary); (2) presence of special exercises concerning synonyms; (3) introduction of metalinguistic knowledge about synonyms (terminology, definitions, and functions). The qualitative analysis dealt with checking whether the synonym-related material meets elementary school standards (set by the Russian Ministry of Education) in terms of its level of difficulty, practical applicability, and representation adequacy (in regard to its creativity components, recycling components, and/or motivational components). Two Russian as L1 textbooks (RTs) and two EFL textbooks (ETs) under discussion were published in Russia and approved by the Russian Ministry of Education for the use in elementary schools.

The results of the textbook analyses yielded several important findings. Disparity between RTs and ETs concerning the representation of synonyms is striking: 87 and 62 synonymic chains in RTs, and 19 and 28 chains in ETs. Whereas this gap can be attributed to the natural difference in vocabulary volume in L1 and L2, the total absence of the exercises dealing with synonyms in L2 textbooks does not provide any reasonable explanation. A possible underlying factor might be an excessive focus on communicative nature of L2 exercises and thus the total absence of any synonyms-related tasks, although working with synonyms is not contradictory to a communicative approach to teaching and can even reinforce it (Chandler, 2008).

Despite the obvious disparity between RTs and ETs in terms of synonym representation, the results of the analyses allow the making of essential connections between L1 and L2 materials for use as a ground for positive transfer. First, RTs provide a fair amount of metalinguistic knowledge on synonymy and its practical applicability enforced through exercises. Second, the number of synonymic chains in ETs is sufficient to design similar exercises encouraging activation of metalinguistic knowledge acquired in L1. Building on those two findings, a system of exercises in Russian and English was designed and aimed at facilitating positive transfer of skills regarding recognition and the use of synonyms in L1 and L2.

\section{Subjects and Method}

In each of the two chosen elementary schools, an experiment was conducted in two classes of third graders: an intervention class (IC) and a control class (CC). The number of 86 participants comprises the following: IC1 - 23, IC2 - 21, CC1 - 20, CC2 - 22 . There were 4 instructors involved in implementing the experimental methodology into the classroom curricula: 2 teachers of Russian as L1 and two teachers of EFL.

At the beginning of the school year, the students of both intervention and control classes took a pretest. The test consisted of three test questions on Russian synonyms and three test questions on English synonyms, while all instructions came in Russian. The three tasks were symmetric and dealt with the following issues: (Task 1) identifying the words similar in meaning by matching them (3 pairs in total), (Task 2) filling in two gaps in one sentence with words similar in meaning depending on their shades of meaning from the options given (2 pairs in total), (Task 3 ) correcting repetitions with the help of synonyms without options given (2 pairs in total). All pairs of synonyms were taken from the textbooks they used in the previous year. The results of the pre-test are shown in Table1.

The results of the pre-test demonstrate that the overwhelming majority of the third-graders are capable of recognizing synonyms both in L1 and L2. In L1 they can also easily find a matching word to avoid repetition from their own vocabulary without being given clues, whereas the same task in L2 turns out to be much more difficult. Yet, the hardest task in both languages is to fill in the gaps with appropriate synonyms according to their shades of meaning, even when the clues to choose fromare given. This last assignment requires an explicit activation of both syntagmatic and paradigmatic links of the word, which apparently is hard for third-graders without special training. At the same time, it is the skill of recognizing distinctions between synonyms and mastering their use in appropriate contexts that determines practical applicability of metalinguistic awareness.

\section{Results and Discussion}

\section{Experiment}

It was crucial to establish collaboration between L1 and L2 instructors so as to promote synchronization of syllabi. The instructors received a set of exercises to incorporate in their intervention classes, and these exercises were synchronized with the textbook they usedthroughout one school year. On average, 
Table 1

Results of the pre-test

\begin{tabular}{|c|c|c|c|c|c|c|c|c|c|c|}
\hline L1 & \multicolumn{10}{|c|}{ Russian } \\
\hline Tasks & \multicolumn{4}{|c|}{ Task 1} & \multicolumn{3}{|c|}{ Task 2} & \multicolumn{3}{|c|}{ Task 3} \\
\hline Number of correct items & 0 & 1 & 2 & 3 & 0 & 1 & 2 & 0 & 1 & 2 \\
\hline Percentage of students in ICs & 0 & 11,4 & 34,1 & 54,5 & 22,7 & 63,7 & 13,6 & 0 & 22,7 & 77,3 \\
\hline Percentage of students in CCs & 0 & 7,2 & 35,7 & 57,1 & 30,6 & 59,9 & 9,5 & 0 & 14,3 & 85,7 \\
\hline L2 & \multicolumn{10}{|c|}{ English } \\
\hline Tasks & \multicolumn{4}{|c|}{ Task 1} & \multicolumn{3}{|c|}{ Task 2} & \multicolumn{3}{|c|}{ Task 3} \\
\hline Number of correct items & 0 & 1 & 2 & 3 & 0 & 1 & 2 & 0 & 1 & 2 \\
\hline Percentage of students in ICs & 4,5 & 45,2 & 38,6 & 11,7 & 68,2 & 29,5 & 2,3 & 6,8 & 70,4 & 22,8 \\
\hline Percentage of students in CCs & 7,2 & 40,5 & 38 & 14,3 & 76,2 & 23,8 & 0 & 11,9 & 64,3 & 23,8 \\
\hline
\end{tabular}

one exercise involving synonyms appeared in Russian and English class once per week. All metalinguistic knowledge regarding the definition and the functions of synonyms was explicitly transmitted by the instructor during Russian classes only, while during English classes, the students were expected to activate this knowledge on their own with the help of scaffolding questions from the teacher. Since third-graders being in their second year of learning English did not possess enough skills to discuss the language material (functions of synonyms) in English, the discussion was conducted in Russian, therefore making room for L1 use in the L2 class. Teachers were also advised to welcome any crosslinguistic comparisons coming from students involving examples from L1.

Taking into consideration the results of the textbook analyses and the data from the pre-test, a system of symmetric exercises in Russian and English was designed, utilizing the vocabulary from the class textbooks and focusing on creating an environment for nurturing language awareness. (On the procedural side, during a week when an exercise was first introduced in L1 class, a matching exercise was given in the L2 class. All instructions for the exercises in both languages were given in Russian.)

The types of exercises according to their learning outcomes included the following:

1. Initial systematization of background knowledge on synonyms.

A. Recognizing synonyms to certain words in the text (usually five simple sentences). Such exercises served as training for retelling.

B. Finding synonyms within a semantic web on a particular topic with further aim to describe some object. This exercise also allows drawing students' attention to other linguistic phenomena, such as antonyms and homonyms, and discussing their peculiarities.

C. Substituting the repeating words in a sentence with their synonyms from a word bank. This activity serves as a preparation to the study of synonym functions.

2. Introduction of terminology and metalinguistic knowledge.

A. Finding synonyms in the text and discussing the shades of meaning (connotation) that help distinguish between them.

B. Discussing examples that show limited interchangeability of synonyms due to register, dialect, or expressivity.

3. Developing the concept of synonyms through training.

A. Showing examples of the various functions of synonyms: specification, substitution, scaling, and/ or euphemization.

B. Learning the skill of using synonyms for inferencing.

C. Discussion of combinability with other words to make collocations.

D. Using synonyms to explain the figurative meaning of words.

E. Recognizing territorial distinctions of synonyms (in case of English, American, and British).

4. Recycling the knowledge and skills on synonyms.

A. Checking text comprehension through synonyms.

B. Error correction using synonyms.

C. Retelling a text using synonyms.

D. Introducing new vocabulary using synonyms and semantic webs.

E. Fostering the use of synonyms (according to their functions) in one's own speech provided a necessity of accomplishing a particular task.

5. Discussing basic cross-linguistic semantic similarities. 
A. Comparing and contrasting synonymic chains in Russian and English.

B. Keeping an open-ended diary-like bilingual dictionary of synonyms.

\section{Results of the Post-Test}

After a school year of being exposed to synonymrelated exercises both in L1 and L2 classes, the students of the intervention classes were post-tested, along with students of control classes, who did not receive the training under discussion. The post-test consisted of the same type of tasks as the pre-test, differing in the language material involved. Post-test included synonymic chains from the third grade textbooks as opposed to the pre-test containing synonyms from the second grade materials. As a result, the level of difficulty was slightly higher, but both groups of the students were exposed to the same language material, but differed in training to accompany it. The results of the post-test are presented in Table 2 .

The figures show an overall gain in knowledge related to synonyms in L1 in both groups of students, possibly due to the presence of material on synonymy in the L1 textbooks used throughout the school year. At the same time, the percentage of students fulfilling all tasks without mistakes demonstrates a higher increase in the intervention classes as opposed to comparison classes. Whereas in Russian an increase of $16 \%$ in ICs compared to null gain in CCs on Task 1 and Task 3 might not be that significant, an increase of $47,8 \%$ on Task 2 in ICs in contrast to $2,4 \%$ gain in CCs can serve as an indicator of the success of experimental methodology. However, the most important results were obtained concerning English: 33,9\% gain on Task 1, 58,8\% gain on Task 2, and 22,7\% gain on Task 3 display evidence of positive transfer of training from
L1 to L2 since metacognitive knowledge in the project was primarily built within L1 classes.

The study adds empirical evidence in favor of concurrent instruction of L1 and L2 and confirms the overall validity of metalinguistic skills training in primary school. As for particular strategy of working with synonyms, the results not only reinforced the idea that synonymy-related skills improve vocabulary comprehension and retention in L1 (Carr, 1985) and are crucial for L2 proficiency (Chandler, 2008), but can also serve as a vehicle for teaching for transfer. Implications of the study include the potential use of metalinguistic knowledge related to other language phenomena such as antonymy or polysemy as tools to foster cross-linguistic transfer, which can serve as subjects for future research. Hopefully, the results of this study will also encourage building bridges across the language curricula in elementary schools in other contexts.

\section{Conclusion}

The study confirms the efficiency of Jessner's (2006) suggestion that 'in order to amalgamate all language subjects, including first and second languages, taught in a school or any other institution, it is necessary to establish a dialogue between the language teachers in order to arrive at a coordination of the aimed at creating linguistic awareness' (p. 131). Instructional strategies of metacognitive skills in L1, which, according to Osman, \& Hannafin (1992), should be explicit for young and novice learners, have proved to be efficient when it comes to working with synonyms in elementary school. The strategy of parallel instruction also showed its effectiveness in

Table 2

Results of the post-test

\begin{tabular}{|c|c|c|c|c|c|c|c|c|c|c|}
\hline L1 & & & & & Rus & $\operatorname{sian}$ & & & & \\
\hline Tasks & & & k 1 & & & Task 2 & & & Task 3 & \\
\hline Number of correct items & 0 & 1 & 2 & 3 & 0 & 1 & 2 & 0 & 1 & 2 \\
\hline Percentage of students in ICs & 0 & 0 & 29,5 & 70,5 & 9 & 29,6 & 61,4 & 0 & 16 & 84 \\
\hline Percentage of students in CCs & 0 & 4,8 & 40,4 & 54,8 & 33,3 & 54,8 & 11,9 & 0 & 16,7 & 83,3 \\
\hline L2 & & & & & Eng & lish & & & & \\
\hline Tasks & & & & & & Task 2 & & & Task 3 & \\
\hline Number of correct items & 0 & 1 & 2 & 3 & 0 & 1 & 2 & 0 & 1 & 2 \\
\hline Percentage of students in ICs & 4,5 & 15,9 & 34 & 45,6 & 4,5 & 36,4 & 61,1 & 4,5 & 50 & 45,5 \\
\hline Percentage of students in CCs & 11,9 & 47,7 & 28,5 & 11,9 & 83,3 & 16,7 & 0 & 33,4 & 47,6 & 19 \\
\hline
\end{tabular}


terms of vocabulary acquisition and its application in fulfilling a communicative task.

\section{References}

Allan, K. K. (1982). The development of young children's metalinguistic understanding of the word. The Journal of Educational Research, 76(2), 89-93.

Antón, M., \& DiCamilla, F. J. (1999). Socio-Cognitive functions of L1 collaborative interaction in the L2 classroom. The Modern Language Journal, 83(2), 233-247.

Bialystok, E. (1986). Factors in the growth of linguistic awareness. Child Development, 57(2), 498-510.

Bialystok, E., \& Ryan, E. B. (1985). Toward a definition of metalinguistic skill. Merrill-Palmer Quarterly, 31(3), 229-251.

Boulware-Gooden, R., Carreker, S., Thornhill, A., \& Joshi, R. (2007). Instruction of metacognitive strategies enhances reading comprehension and vocabulary achievement of third-grade students. The Reading Teacher, 61(1), 70-77.

Cárdenas-Hagan, E., Carlson, C. D., \& PollardDurodola, S. D. (2007). The cross-linguistic transfer of early literacy skills: The role of initial L1 and L2 skills and language of instruction. Language, Speech, and Hearing Services in Schools, 38(3), 249259.

Carr, E. M. (1985). The vocabulary overview guide: A metacognitive strategy to improve vocabulary comprehension and retention. Journal of Reading, 28, 684-689.

Corder, S. P. (1993). A role for the mother tongue. In S. Glass \& L. Selinker (Eds.), Language Transfer in Language Learning (Vol. 5, pp. 18-31). Philadelphia, PA: John Benjamins Publishing Company.

Chandler, P. M. (2008). The appropriate teaching of vocabulary: What the research suggests. Hispania, 9(1), 247-248.

Cummins, J. (2005). Teaching for cross-language transfer in dual language education: Possibilities and pitfalls. In TESOL Symposium on dual language education: Teaching and learning two languages in the EFL setting (pp. 1-18). Istanbul, Turkey: Boğaziçi University.

Engle, R. A., Lam, D. P., Meyer, X. S., \& Nix, S. E. (2012). How does expansive framing promote transfer? Several proposed explanations and a research agenda for investigating them. Educational Psychologist, 47(3), 215-231.

Fess, G. M. (1938). Teaching synonyms. English Journal, 27, 347-349.
Furnas, E. (1908). The study of synonyms as an aid in the acquisition of a vocabulary. The School Review, 16(2), 115-118.

Gass, S., \& Selinker, L. (Eds.). (1993). Language transfer in language learning. Amsterdam, Netherlands: J. Benjamins Publishing Company.

Herrarte, D. L. (1998). Metalinguistic awareness and the learning of English as an L3. Atlantis, 20(2), 69-79.

Jarvis, S., \& Pavlenko, A. (2008). Crosslinguistic influence in language and cognition. Abingdon, UK: Routledge.

Jessner, U. (2008). A DST model of multilingualism and the role of metalinguistic awareness. The Modern Language Journal, 92(2), 270-283.

Jessner, U. (2006). Linguistic awareness in multilinguals: English as a third language. Edinburgh, UK: Edinburgh University Press.

Odlin, T. (1989). Language transfer: Cross-Linguistic influence in language learning. Cambridge, UK: Cambridge University Press.

Osman, M. E., \& Hannafin, M. J. (1992). Metacognition research and theory: Analysis and implications for instructional design. Educational Technology Research and Development, 40(2), 83-99.

Perkins, D. N., \& Salomon, G. (2012). Knowledge to go: A motivational and dispositional view of transfer. Educational Psychologist, 47(3), 248-258.

Ringbom, H. (2007). Cross-Linguistic similarity in foreign language learning (Vol. 21). Bristol, UK: Multilingual Matters.

Royer, J. M. (1979). Theories of the transfer of learning. Educational Psychologist, 14(1), 53-69.

Royer, J. M., \& Carlo, M. S. (1991). Transfer of comprehension skills from native to second language. Journal of Reading, 34(6), 450-455.

Tunmer, W. E., Herriman, M. L., \& Nesdale, A. R. (1988). Metalinguistic abilities and beginning reading. Reading Research Quarterly, 23, 134-158.

van der Leij, A., Bekebrede, J., \& Kotterink, M. (2010). Acquiring reading and vocabulary in Dutch and English: The effect of concurrent instruction. Reading and Writing, 23(3-4), 415-434.

van Kleeck, A. (1982). The emergence of linguistic awareness: A cognitive framework. Merrill-Palmer Quarterly, 28(2), 237-265.

Verhoeven, L. T. (1994). Transfer in bilingual development: The linguistic interdependence hypothesis revisited. Language Learning, 44(3), 381-415.

Vygotsky, L. (1934). 1986. Thought and language. Cambridge, MA: Harvard University Press.

Zipke, M. (2008). Teaching metalinguistic awareness and reading comprehension with riddles. The Reading Teacher, 62(2), 128-137. 